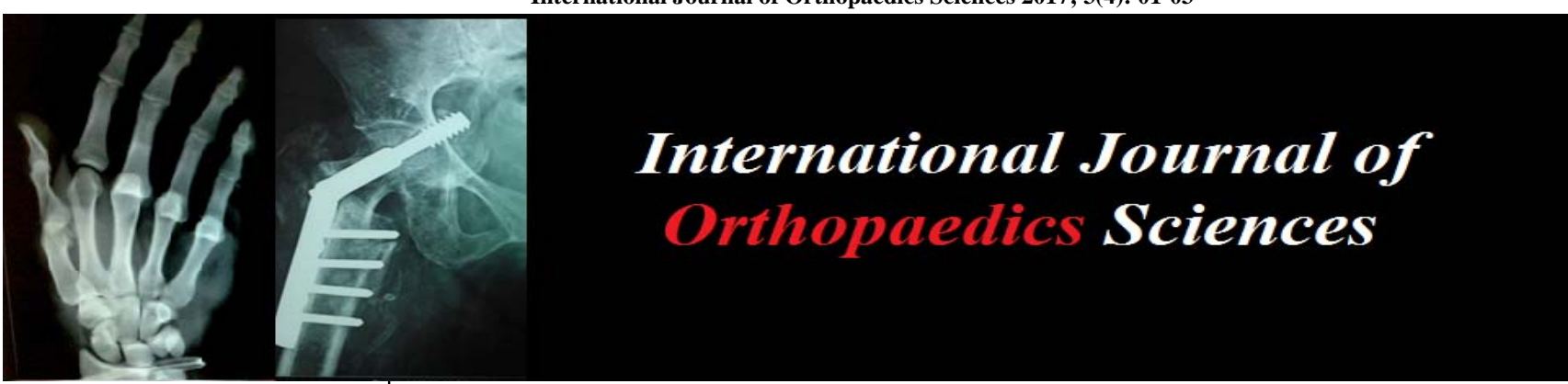

ISSN: $2395-1958$

IJOS 2017; 3(4): 01-03

(C) 2017 IJOS

www.orthopaper.com

Received: 01-08-2017

Accepted: 02-09-2017

Shashi Kant Suman

Senior Resident, Department of

Orthopaedics, RIMS, Ranchi,

Jharkhand, India

Ashok Kumar Meena

PGT, Department of

Orthopaedics, RIMS Ranchi,

Jharkhand, India

\section{LB Manjhi}

Associate Professor \& Hod, Department of Orthopaedics, RIMS, Ranchi, Jharkhand, India

Shashi Kant Kumar Singh PGT, Department of Orthopaedics, RIMS Ranchi, Jharkhand, India
Correspondence

Shashi Kant Suman

Senior Resident, Department of

Orthopaedics, RIMS, Ranchi,

Jharkhand, India

\section{Open interlocking nailing of the fracture of the shaft of tibia}

\author{
Shashi Kant Suman, Ashok Kumar Meena, LB Manjhi and Shashi Kant \\ Kumar Singh
}

DOI: https://doi.org/10.22271/ortho.2017.v3.i4a.01

\section{Abstract}

Closed Interlocking intramedullary nail is now the standard in the treatment of tibial shaft fractures however use of image intensifier precludes its common use in developing countries. This study was done to evaluate the outcome of open interlocking nailing under heading of fracture union, early mobilisation and early functional return of the limb and complication. We retrospectively reviewed 36 patients with Fracture shaft of tibia treated with open interlocking nailing. All fractures were simple transverse, short oblique. Serial follow up assessment was done for radiological and clinical union. Major complications encountered were infection. It was concluded that open interlocking nailing is a safe procedure for tibial shaft fractures, in the developing worlds with good functional and clinical results in the following situations: in hospitals with no image intensifier, in irreducible fractures and in female patients with pregnancy.

Keywords: Open interlocking nailing, distal locking zig, tibial shaft fracture

\section{Introduction}

Open $v$ nailing is no longer the common method of fixation of the tibial shaft fracture now a day as interlocking nail offers good control of limb length and rotational alignments. However availability of image intensifier has been a major factor against the wide spread use especially in developing countries. We have done a retrospective study on 36 patients treated by open interlocking nail at RAJENDRA INSTITUTE OF MEDICAL SCIENCES, RANCHI, Jharkhand. This study was done to evaluate the use of open interlocking nail with regard to time of union, infection, limb length and range of motion at the knee without image intensifier with added benefits on surgeons part of less expertise, less surgery time, and good to excellent union rates and at the same time on patients part, avoidance of radiological exposure, being economical availability at the next door itself

\section{Methods}

Open interlocking nailing using proximal and distal locking zig was done in 36 patients during April 2015 to June 2016 at RAJENDRA INSTITUTE OF MEDICAL SCIENCES, RANCHI, Jharkhand, INDIA. Among 36 patient 28 patient was male and 8 patient was female having age between 19-45 years having 40 fracture of the shaft of the tibia (4 patient having bilateral fracture). According to the X-ray, the fracture was classified according to the site, pattern \& comminution. Open fractures and more comminuted fracture not included in the study. These 40 fractures were fixed within 6-7 days by open intramedullary nailing, locking done with distal locking zig without image intensifier.

\section{Procedure}

In this method guide wire was inserted through just above the tibial tuberosity. Open reduction of the fracture was done and guide wire was passed up to the distal tibia. The length of the nail was measured from tibial tuberosity up to $2 \mathrm{~cm}$ proximal to medial malleolus. The diameter of the nail was assessed according to the final reamer used at the time of surgery. The distal interlocking zig was mounted on the proximal end of the selected nail by bolt and tightened. The rotation and axis of the nail was checked with the position of the zig arm. 
All assembly was tightened snugly. The zig arm has holes at different distances for distal locking corresponding to the nail size used (fig 1). Through these holes, protection sleeve is inserted. Through a $2 \mathrm{~cm}$ incision on the distal leg corresponding to the determined hole, sleeve was passed up to bone and then drilling was done. After confirming correct drill position by striking guide wire to drill bit, screw size was measured through the sleeve, and a proper size of $4 \mathrm{~mm}$ selftapping screws was inserted and tightened. Position confirmed by striking guide wire to bolt. After removal of guide wire, with the help of same zig insertion of proximal locking screw was done.

\section{Post-operative care \& follow-up}

Static quadriceps and ankle mobilisation exercise was started the next post-operative day. After removal of sutures on 13th post-operative day knee mobilisation exercises started. Partial weight bearing was allowed at 6 weeks. In some cases dynamisation was done at 8 weeks and patient was ambulating with the help of crutches. Full weight bearing was allowed on the radiological evidence of callus consolidation. The patients were followed at monthly intervals for 3 months regularly, then at $6^{\text {th }}$ month, $9^{\text {th }}$ month and finally at $12^{\text {th }}$ month.

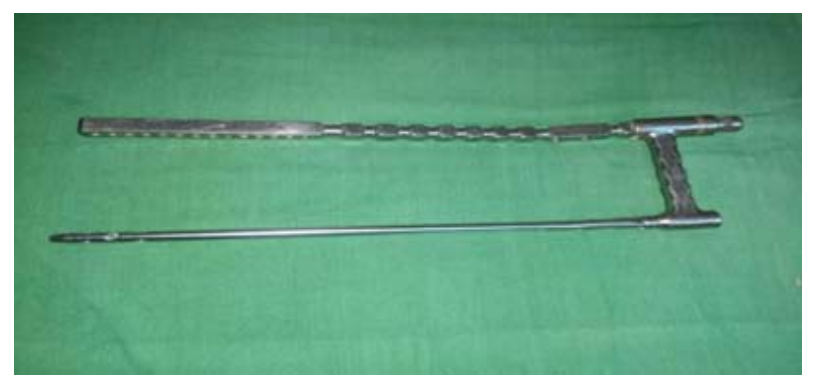

Fig 1: Distal locking zig arm has holes at different distances for distal locking and two proximal holes for proximal locking

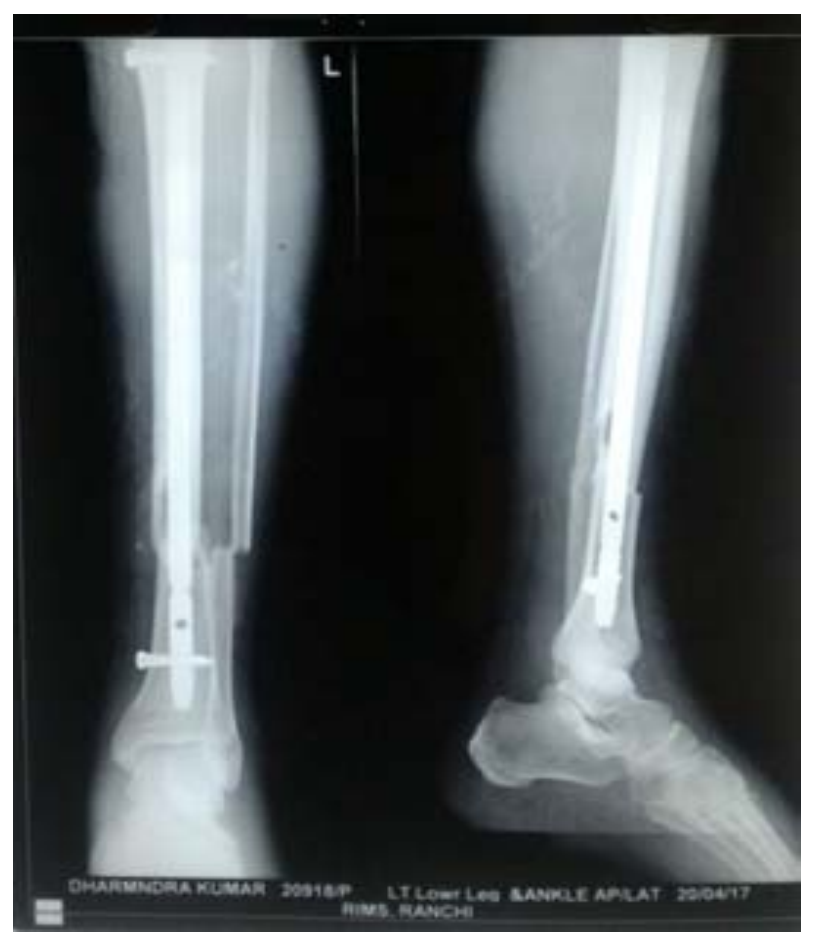

Fig 2: Post op immediate x-ray of 19 year old patient having fracture shaft of tibia treated with open interlocking nailing (Missed one distal screw)

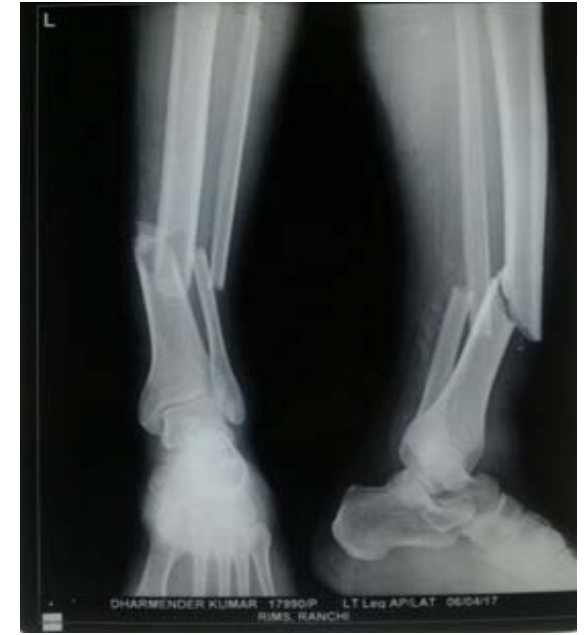

Fig 3: x-ray of 30year old patient having fracture shaft of tibia and fibula

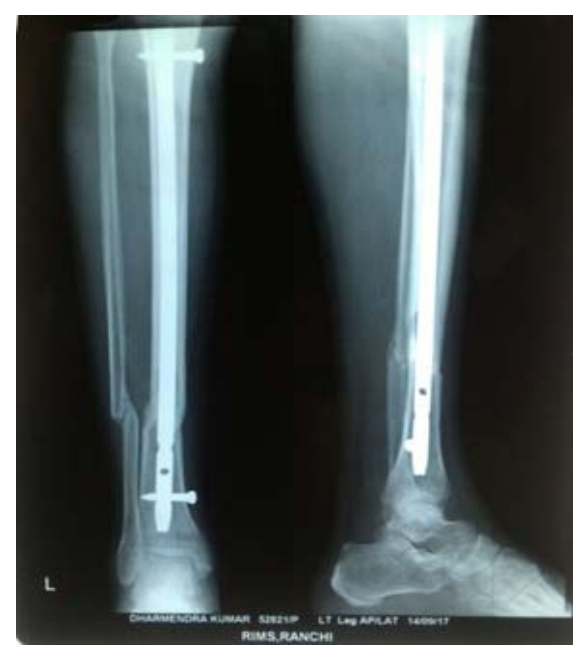

Fig 4: X-ray of the same patient after 5 month showing complete union

\section{Result}

Male to female ratio was 3.5: 1 and 30 patients were in the 3rd and 4th decades. According to the site of fracture, 2 were at proximal third, 26 at middle third and 12 were at distal third of tibial shaft. The union rate was $92.5 \%$. The breakup of union according to time is shown in table 1 . The complications which were noted are shown in table 2. Range of motion at hip and knee was full after 12 weeks. Dynamization were done in 10 cases at 8 weeks post operatively. In one case screw bend occurs due to early weight bearing

Table 1

\begin{tabular}{|c|c|c|}
\hline Time & No of cases & Percentage (\%) \\
\hline Within 3 months & 01 & 2.5 \\
\hline Within 6 months & 17 & 42.5 \\
\hline Within 9 months & 31 & 77.5 \\
\hline Within 12 months & 34 & 85 \\
\hline Non union & 3 & 7.5 \\
\hline Total & 40 & 100 \\
\hline
\end{tabular}

Table 2

\begin{tabular}{|c|c|c|}
\hline complication & No of cases & percentage \\
\hline Non union & 03 & 7.5 \\
\hline infection (superficial) & 03 & 7.5 \\
\hline
\end{tabular}




\section{Discussion}

Various modalities of treatment have been suggested for treating fracture long bones. Closed nailing and closed interlocking were introduced after the advent of image intensifier. Majority of these fractures satisfactorily treated by close inter locking nail, but in Indian health infrastructure particularly at rural centres where the facility of image intensifier not available and referral centres are situated at long distances, it is not the method of choice and open nailing with proximal and distal locking with the help of distal locking zig arm should be considered as the modality to treatment. Ours aim is targeting to that area of health system, so that the treatment of fracture shaft tibia could be made available at the at the rural/basic health structure level. 92.5\% fractures united in the present series in the period of 12 months. In this study nature of bridging callus with partial obliteration of fracture site has been used as time for union which was 8 weeks.

Open interlocking nailing with a predictable surgical time procedure is less expensive, easy and more convenient for less experienced newly qualified orthopaedic surgeon, only fewer instruments are required. Due to the direct observation of bone may lead to absolute anatomic reduction which some time not possible with close interlocking procedure. In comparison to the closed method, rotational mal-alignment is rare after open reduction. In non-union opening of the medullary canals of the sclerotic bone is easier, and it required simultaneous bone grafting can be considered. But surgical skin scar, increased blood loss, loss of fracture haematoma (which is more important in fracture healing) increased infection rate, and complication rate and decreased rate of union has its own demerits in open IL nailing procedure.

\section{Conclusion}

Closed Interlocking intramedullary nails is now the standard in the treatment of tibial shaft fractures however cost, use of image intensifier precludes its common use in developing countries. But an open version of this procedure, by which the fracture is stabilized by opening the fracture site, became popular because of less complication and more predictable operating time.

Method of open nailing can be considered at rural health centres in Indian health scenario as comparably good results could be obtained with less expertise required and avoiding the radiological hazards and giving surgical assistance at a very economical basis. This additional benefit could be added by doing locking of the nail at proximal and distal levels with the help of distal locking zig arm without the help of image intensifier, without hampering the benefits of open nailing. Keeping the multiple factors in mind like overcrowded orthopaedics wards with fracture tibia, early disposal of the patient, less resources and unequipped peripheral hospitals (no facility of image intensifier and fracture table) and to avoid the hazards of radiation and various other benefits of open nailing, it was decided to conduct a study of open interlock nailing in fracture tibia. Hence a plan was made to study the result of open-interlocking nailing.

\section{References}

1. Alho A, Benterud JG, Hogevold HE, Ekeland A, Stromsoe K. Comparison of functional bracing and locked intramedullary nailing in the treatment of displaced tibial shaft fractures. Clin Orthop Relat Res. 1992; 277:243-250.
2. Bhandari M, Adili A, Leone J, Lachowski RJ, Kwok DC. Early versus delayed operative management of closed tibial fractures. Clin Orthop Relat Res. 1999; 368:230239.

3. Bishop JA, Dikos GD, Mickelson D, Barei DP. Open reduction and intramedullary nail fixation of closed tibial fractures. Orthopedics. 2012; 35:e1631-1634.

4. Blachut PA, O’Brien PJ, Meek RN, Broekhuyse HM. Interlocking intramedullary nailing with and without reaming for the treatment of closed fractures of the tibial shaft. A prospective, randomized study. The Journal of Bone and Joint Surgery. American. 1997; 79:640-646.

5. Chan DS, Burris RB, Erdogan M, Sagi HC. The insertion of intramedullary nail locking screws without fluoroscopy: A faster and safer technique. J Orthop Trauma. 2013; 27:363-6.

6. Chen AL, Tejwani NC, Joseph TN, Kummer FJ, Koval KJ. The effect of distal screw orientation on the intrinsic stability of a tibial intramedullary nail. Bulletin (Hospital for Joint Diseases New York, NY. 2001-2002; 60:80-83.

7. Fan CY, Chiang CC, Chuang TY, Chiu FY, Chen TH. Interlocking nails for displaced metaphyseal fractures of the distal tibia. Injury. 2005; 36:669-674

8. Hoppenfeld S, deBoer P. Surgical Exposures in Orthopaedics. 3rd ed. Philadelphia, PA: Lippincott Williams \& Wilkins, 2003.

9. Im GI, Tae SK. Distal metaphyseal fractures of tibia: A prospective randomized trial of closed reduction and intramedullary nail versus open reduction and plate and screws fixation. Journal of Trauma. 2005; 59:1219-1223

10. Klemm KW, Boerner M. Interlocking nailing of complex fractures of the femur and tibia. Clin Orthop. 1986; 212:89-100.

11. Keating JF, Orfaly R, O’Brien PJ. Knee pain after tibial nailing. J Orthop Trauma. 1997; 11(1):10-13.

12. Langfitt MK, Halvorson JJ, Scott AT, Smith BP, Russell $\mathrm{GB}$, Jinnah RH, et al. Distal locking using an electromagnetic field-guided computer-based real-time system for orthopaedic trauma patients. J Orthop Trauma. 2013; 27:367-72.

13. Moreschini O, Petrucci V, Cannata R. Insertion of distal locking screws of tibial intramedullary nails: a comparison between the free-hand technique and the SURESHOT ${ }^{\mathrm{TM}}$ Distal Targeting System. Injury. 2014; 45:405-7.

14. Nicoll EA. Fractures of the tibial shaft: a survey of 705 cases. J Bone Joint Surg. 1964; 46-B:373-87.

15. Roberts CS, King D, Wang M, Seligson D, Voor MJ. Should distal interlocking of tibial nails be performed from a medial or a lateral direction? anatomical and biomechanical considerations. Journal of Orthopaedic Trauma. 1999; 13:27-32.

16. Tang P, Gates C, Hawes J, Vogt M, Prayson MJ. Does open reduction increase the chance of infection during intramedullary nailing of closed tibial shaft fractures? J Orthop Trauma. 2006; 20:317-22. 